\title{
AGAINST ALL ODDS: INSIDE STATISTICS
}

\author{
Marsha Davis \\ Department of Mathematics and Computer Science \\ Eastern Connecticut State University, Willimantic, CT, USA \\ davisma@easternct.edu
}

Given the importance of statistics and statistical reasoning in an increasingly complex and information rich-world, ways must be found to engage students with real-world contexts and activities that support learning the basic elements of statistical thinking and the important concepts that underlie statistical reasoning, particularly concepts that students find difficult. Online resources from the newly released Against All Odds (AAO): Inside Statistics (funded by Annenberg and the Consortium for Mathematics and Its Applications (COMAP)) are designed to do just that. The videos, activities, interactive applets, exercises, and written support in AAO provide a rich learning environment that makes statistics come alive and promotes deeper understanding. This presentation will focus on a video and an applet and related class activities. Results from class testing will be shared.

\section{BACKGROUND}

Over the years, the number of sections of Introductory Statistics has greatly increased. Students enrolled in Introductory Statistics have diverse backgrounds, interests, and reasons for taking the course. All too often Introductory Statistics is viewed as unpleasant, difficult, and/or boring by students (Garfield, Hogg, Schau, \& Whittinghill, 2000). Given the importance of statistics and statistical reasoning in an increasingly complex and information-rich world, ways must be found to engage students with real-world contexts and activities that support learning the basic elements of statistical thinking and the important concepts that underlie statistical reasoning, particularly concepts that students find difficult.

Against All Odds: Inside Statistics (AAO) is an online resource that consists of 30 modules on topics on descriptive statistics, probability, and inference. Each module consists of a video, an activity (some of which use interactive applets), written support material, and exercises that involve real-world data and use of technology. $A A O$ materials can be used either as the course materials or as supplements to other course materials. With careful selection and a bit of creativity, AAO materials can be adapted for use with a wide range of students; for example, material could be adapted for use in middle school, a college introductory statistics course for mathematics majors, or for teacher professional development (particularly preparing teachers for the statistics and probability content in the Common Core State Standards for Mathematics.)

\section{MATERIALS}

This paper describes one video module, The Happiness Survey, and one of the interactive tools, Wafer Thickness, and discusses how the video and applet can be used to enliven a statistics class and to support student learning of difficult concepts.

\section{Two-Way Tables: The Happiness Survey}

We are bombarded by surveys. We click on the Internet and up comes a survey. We buy a product online, and we are asked to fill out a survey. During political races, the airwaves are filled with reports on results of surveys. Analyzing categorical survey data one question at a time is not very difficult but it is also not very interesting. The interesting results come from investigating the relationships between responses to two (or more) questions, in other words, analyzing two-waytables' data. Even though college students (even mathematics majors!) struggle with this topic, it has worked its way into the Common Core State Standards for High School Mathematics (S-ID-5). AAO's unit Two-Way Tables is a great place for students to start and can help them sort out the difference between, for example, the percentage of women who are Democrats and the percentage of Democrats who are women. The context for the video is a Happiness Survey that was part of Somerville, Massachusetts' 2011 annual census. The video focuses on two of the survey questions, one that asks respondents to rate their current level of happiness and the other that asks them to rate 
the beauty of Somerville. Happiness ratings are boiled down into three categories: Unhappy, So-So, and Happy. Ratings of Somerville's physical beauty are categorized as Bad, OK, and Good. Results from these two questions are organized into Table 1.

Table 1. Results from rating happiness and Somerville’s physical beauty.

\begin{tabular}{|l|l|r|r|r|r|}
\cline { 3 - 5 } \multicolumn{2}{c|}{} & \multicolumn{3}{c|}{ Physical Beauty } & \multirow{2}{*}{ Total } \\
\cline { 3 - 5 } Happiness & Bad & OK & Good & Tot \\
\hline \multirow{3}{*}{ Haynnn} & Unhappy & 90 & 123 & 62 & 275 \\
& So-so & 555 & 972 & 610 & 2137 \\
& Happy & 541 & 1426 & 1406 & 3373 \\
\hline \multicolumn{2}{|c|}{ Total } & 1186 & 2521 & 2078 & 5785 \\
\hline
\end{tabular}

From here students can easily find the marginal distributions of Happiness and Physical Beauty. A majority of Somerville's residents (58\%) responded that they were happy and $44 \%$ rated the physical beauty of Somerville as OK.

One interesting question that cannot be answered by analyzing one question at a time is whether happy people have a more positive view of Somerville, in terms of beauty, than unhappy people. For that we need to compute the conditional distributions of Physical Beauty for each Happiness category (Table 2).

Table 2. Conditional distribution of Physical Beauty for each Happiness category.

\begin{tabular}{|c|c|c|c|c|c|}
\hline & & \multicolumn{3}{|c|}{ Physical Beauty } & \multirow[b]{2}{*}{ Total } \\
\hline & & Bad & OK & Good & \\
\hline \multirow{3}{*}{ Happiness } & Unhappy & $32.73 \%$ & $44.73 \%$ & $22.55 \%$ & $100 \%$ \\
\hline & So-so & $25.97 \%$ & $45.48 \%$ & $28.54 \%$ & $100 \%$ \\
\hline & Happy & $16.04 \%$ & $42.28 \%$ & $41.68 \%$ & $100 \%$ \\
\hline
\end{tabular}

From Table 2 we discover that only 23\% of unhappy residents rated Somerville's beauty as Good compared to around $42 \%$ of happy people. Clearly there is linkage between the Happiness and Physical Beauty variables. Upon further inspection, we note that as the level of Happiness goes up, the percentage of Bad ratings for Physical Beauty goes down. In addition, as the level of Happiness goes up, the percentage of Good ratings also goes up. Now that Somerville has identified a link between residents' happiness levels and their thoughts on the city's physical beauty, officials want to dig deeper on the next survey in an effort to improve residents' satisfaction with Somerville.

The activity for the Two-Way Tables unit is for students to conduct a Happiness Survey of students in their class or school. In fact, for the last two years, I have conducted my own Happiness Survey on the first day of class. (I have added a few questions; for example, students have listed their year, which has produced some interesting results. It appears that a higher percentage of juniors are happy on the first day of class compared to seniors and yes, happy students are more likely to rate the physical beauty of campus as good compared to unhappy students.)

\section{Wafer Thickness Interactive}

Over twenty years ago, Cobb (1991) provided a direction for improving the teaching of Introductory Statistics: "Almost any course in statistics can be improved by more emphasis on data and concepts, at the expense of less theory and fewer recipes. To the maximum extent feasible, calculations and graphics should be automated. Any introductory course should take as its main goal helping students to learn the basics of statistical thinking.” Moore (1990) put understanding variability - its omnipresence and appropriate ways to quantify and model variability - at the core of his description of statistical thinking. "Yet when most students first encounter statistics, they find that variability plays second fiddle to "central tendency" (Gould, 2004). Activities based on $A A O$ 's Wafer Thickness interactive applet provide a way to address this problem. 
The Wafer Thickness interactive (www.learner.org/courses/againstallodds/) simulates measuring the thickness of polished wafers used in the production of microchips. Figure 1 shows a screen capture of the applet in action measuring in real-time the thickness of the second wafer in a sample of size five. Using the applet, students can adjust three controls governing the production process and then collect data on the thickness of the polished wafers. The applet lists the thickness measurements of each wafer and creates a histogram of the data. Using the applet, students can compare histograms of up to three samples of data. In addition, the data can be saved as a csv file for further analysis using spreadsheet or statistical software.

\section{Real-Time Mode Jump-to-Results Mode Instructions Learning Outcomes}

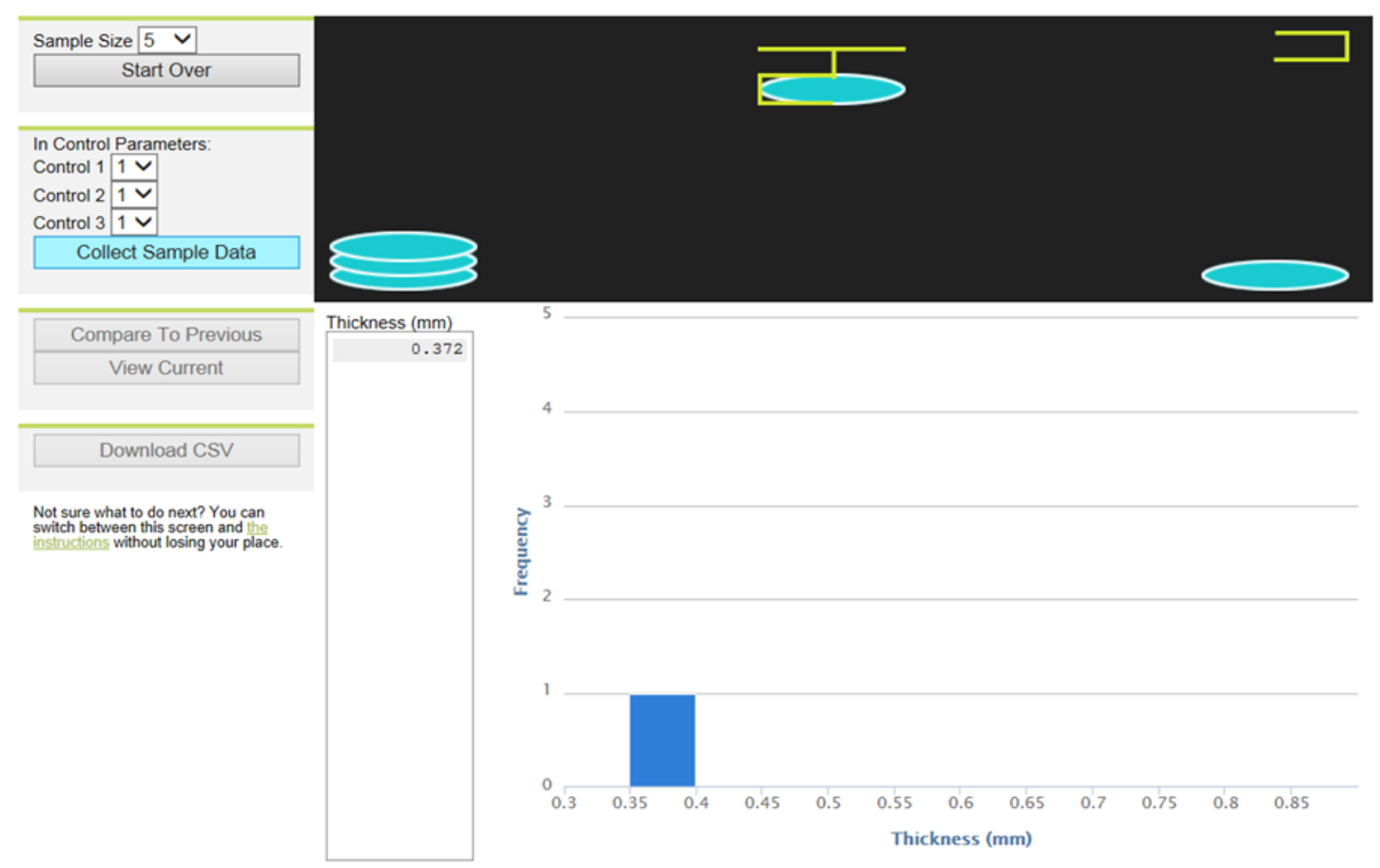

Figure 1. Wafer Thickness interactive.

In the first activity, students collect data produced under a variety of control settings. Based on the histograms, students make recommendations for the optimal control settings in order to produce polished wafers that are consistently close to a specified target thickness. This makes a great starter activity. This activity has been class tested in a variety of settings (introductory statistics courses for both math and non-math majors, in-service course for teachers at the graduate level, and with middle school students) and the following has been observed:

- Students were totally engaged in the activity. Each group had their own data. The group data varied from group to group.

- Students observed that in a sample of wafers produced under the same control settings, wafer thickness varied from wafer to wafer.

- Students discovered that distributions of wafer thicknesses differed from sample to sample even when produced under the same control settings.

- Even with the noise in the data related to the previous two bullets, students were able to describe patterns in how the levels of the control settings affected wafer thickness. So, now we have variation due to the control settings.

- Students used their own informal language to describe the shapes of the histograms prior to the introduction of more formal descriptors (such as unimodal or skewed), a practice supported by research (Garfield \& Ben-Zvi, 2008). 
- In order to compare wafer thickness under different control settings, students created informal measures of both center and spread.

- Groups did not arrive at a single definitive answer. While some recommendations were better than others, the best choice for settings pitted getting the center as close to the target as possible against trading reduced variability for a center that was slightly farther from the target.

In a follow-up activity, students imported the data into a statistics package and were able to look at a variety of graphical representations and compute numeric summaries to add to their information descriptors from the first activity. In an introductory statistics course for mathematics majors, revisiting this activity provided an opportunity to discuss triangular distributions (the underlying model for the applet's randomly generated data) and to revisit the solution to the problem using theory.

The Wafer Thickness applet can also produce data for analysis of variance (ANOVA), a topic typically covered at the end of a semester. ANOVA is particularly difficult for students to grasp, because here we establish a difference in means by analyzing variation. In this activity the question is whether mean wafer thickness differs depending on control levels for each control separately. In Experiment 1, control 1 is varied from 1 to 2 to 3 while controls 2 and 3 are held fixed at level 2. In Experiment 2, control 2 is allowed to vary and in Experiment 3 control 3 is allowed to vary. For each experiment, samples of size 10 are collected in Real Time mode so that students can watch the data being collected. The data can be copied by hand and analyzed using a graphing calculator or exported for analysis with spreadsheet or statistical software. Because the applet generates random data, each student (or group of students) will be working with different data. However, the results will generally be similar:

- For control 1, the mean thickness differs significantly among control levels.

- For control 2, the mean thickness among control levels is not significant.

- For control 3, the underlying assumption of equal standard deviations for ANOVA is not satisfied.

After individuals or groups have completed the activity, there is the opportunity to share results. Students can then see for themselves that the same experiment results in different values for the F-statistic. In most cases the conclusions are the same. However, it is possible that one individual/group's conclusions could differ from the majority due to sampling variability.

\section{CONCLUSION}

Providing students with opportunities to see statistics in action and activities where students can collect and analyze their own data can engage students and support their learning of difficult concepts.

\section{REFERENCES}

Cobb, G. (1991). Teaching statistics: More data, less lecturing. Amstat News, 182, 1-4.

Common Core State Standards Initiative. (2010). Common Core State Standards for Mathematics. www.corestandards.org/Math

Garfield, J., \& Ben-Zvi, D. (2008). Developing students' statistical reasoning: Connecting research and teaching practice. New York: Springer.

Garfield, J., Hogg, B., Schau, C., \& Whittinghil, D. (2000). Best practices in introductory statistics. Position paper prepared for the Undergraduate Statistics Education Initiative.

Garfunkel, S., Davis, M., \& Villiger, M. (2013). Against all odds: Inside statistics. Washington, DC: Annenberg Learner. www.learner.org/courses/againstallodds/

Gould, R. (2004). Variability: One statistician's view. Statistics Education Research Journal, 3(3), 7-16.

Moore, D. (1990). Uncertainty. In L. Steen (Ed.), On the shoulders of giants: New approaches to numeracy (pp 95 - 138). Washington, DC: National Academy Press. 